\title{
Genetic diversity and association analysis among Egyptian barley (Hordeum vulgare L.) genotypes with different adaptations to saline conditions analyzed by SSR markers
}

\author{
Ammar Elakhdar ${ }^{1,2,3}$, Mohamed Abd El-sattar², Khairy Amer ${ }^{3}$ and Toshihiro Kumamaru ${ }^{\text {* }}$ \\ ${ }^{1}$ Laboratory of plant Genetic Resources, Institute of Genetic Resources, Faculty of Agriculture, Kyushu \\ University, Hakozaki 6-10-1, Fukuoka 812-8581, Japan \\ ${ }^{2}$ Crops Science Department, Faculty of Agriculture, Alexandria University, Elshatby 21545, Aflaton St, Egypt \\ ${ }^{3}$ Barley Research Department, Field Crops Research Institute, Agricultural Research Centre, 9 Gama St., Giza, \\ Egypt
}

\author{
*Corresponding author: kumamaru@agr.kyushu-u.ac.jp
}

\begin{abstract}
The success of salt tolerance breeding programs employing traditional screening and selection has been limited in the past decades. This study was designed to characterize the genetic diversity within a subset of barley germplasm using microsatellite markers under different adaptations to salt conditions. Twenty-five microsatellites (SSR) representative of the barley genome, were used in 30 barley accessions and cultivars. A total of 59 alleles were generated, the mean number of alleles per locus was 2.4 and the PIC was 0.22. The four genomic Locus Bmac0030, Bmag0125, EBmac0701 and EBmac0871 were sufficient to differentiate the diversity of all genotypes since they generated a high number of allele with high PIC values. Cluster analysis UPGMA based on SSRs data clearly the most differentiate genotypes according to their Salinity tolerance and the PCA recorded $58.8 \%$ of the total variance. Five markers pairs were found to be associated with salinity and showed linkage disequilibrium with $\mathrm{r}^{2}$ values higher than 0.05 . Association analysis along with specific significant alleles of grain yield showed a significant association of the marker Bmag749 $(2 \mathrm{H}, 176 \mathrm{bp})$ with salinity. Our results shown a small sample and limited markers were used in this study and the results need to be confirmed using linkage mapping with a large association population. However, the results are credible because many of the loci that were identified were associated with traits that were common with previous reports of linkage or association mapping. These will be useful for molecular marker assist selection and molecular design breeding.
\end{abstract}

Keywords: Barley, salinity tolerance, DNA markers, Linkage Disequilibrium, Microsatellites, principal Components analysis. Abbreviations: EC_Electric conductivity; SSR_ simple sequence repeat; PCA _ Principal Components Analysis.

\section{Introduction}

Barley (Hordeum vulgare L.) has a long history as a domesticated crop, as one of the first crops adopted for cultivation. Migration of people together with their crop seeds led to a major diversification and adaptation to new areas, and the crop is now virtually found worldwide. Conscious selection of desired genotypes by farmers at any early stage, together with natural selection, increased the diversity and created the rich gene pool source of variation found today in local varieties. The development of new technology and methods increased the genetic diversity even further and turned barley into the universal, highly diverse crop Harlan, (1976).

Salinity is one of the major obstacles to increasing crop productivity. Some of the most severe problems in soil salinity occur in arid and semiarid regions of the world. Besides these regions, salinity also affects agriculture in coastal regions and areas affected by low-quality irrigation water. Salt tolerance of barley plants is affected by soil conditions. In dry saline soils, the primary limiting factors for plant growth and development are high $\mathrm{pH}$ and sodicity (Barrett-Lennard, 2003; Colmer et al., 2005).

Germination and seedling growth under saline environment are the screening criteria which are widely used to select the salt tolerance genotype (Adjel et al., 2013; El Goumi et al., 2014; Yousofinia et al., 2012). Salt tolerance of most species including barley varies with plant growth stage. Barley is most sensitive to salinity at germination and young seedling stage, and exhibits increased tolerance with age. Salt stress for barley at seedling stage has been mainly attributed to ionic effects rather than to osmotic effects (Storey and Wyn, 1978).

Genetic diversity between parental genotypes is usually estimated by measurements of physiological and morphological differences of quantitative and economically important traits. The disadvantages of this conventional approach are the cost of time and labour during the measurements, and the influences of environmental factors. Often, these disadvantages are exacerbated in salt-tolerance breeding. For example any change in the environment such as temperature, light or humidity can dramatically change the transpiration driving forces and, subsequently, ion uptake Jaiwal, (1997), Such changes may alter salt tolerance among genotypes. It is important to note that morphological characters are often limited in their numbers and may not adequately represent actual genetic relationships among genotypes.

Conversely, identified genetic variations based on DNA polymorphism are abundant and independent of the environmental factors Garland et al. (1999). Microsatellite markers are very useful for plant breeding and genetic 
diversity studies for several reasons. They require only small amounts of sample DNA, easy to amplify by polymerase chain reaction (PCR), amenable to high-throughput analysis, largely co-dominantly inherited, multi-allelic, highly informative and abundant in plant genomes Powell et al. (1994).

In barley, more than 775 microsatellites have been published Varshney et al. (2007), and genetic maps based on microsatellites for all seven barley chromosomes are publicly available (Saghai Maroof et al., 1994; Ramsay et al., 2000).

Novel association mapping or linkage disequilibrium approaches have recently been introduced in plant genetic studies (Mackay and Powell 2007; Cockram et al., 2010). Association mapping studies in a much broader germplasm are now possible due to fast and affordable genotyping and sequencing technologies (Zhu et al. 2008). Association mapping relies on linkage disequilibrium between markers and QTLs present in collections of diverse germplasm Pritchard et al. (2000). It exploits the recombination events that have occurred during the long evolutionary history (Nordborg and Tavare 2002) of a crop species, producing shorter linkage blocks than found in bi-parental QTL mapping studies.

The objective of this study was to investigate the genetic diversity of 30 barley accessions. These lines, were composed of lines tested for salinity tolerance, elite lines and varieties with good agronomic performance. Additionally, association trait analysis was conducted for grain yield, number of grain per spike, 1000-grain weight, Leaf area and chlorophyll content under salinity condition.

\section{Results}

\section{Analysis of variance (ANOVA) and mean performance}

Analysis of variance for five traits of thirty barley genotypes (Supplementary Table 1) in each study season, revealed accepted homogeneity of errors Bartlett, (1937). The pertinent mean squares for those characters across seasons were illustrated in (Table 1). The tested barley genotypes significantly differed in all five tested traits. Also, genotypes had characters of different magnitude or ranked in each study season (significance season $\times$ genotype interaction). The only measured character that had not significantly varied with seasons was the No. grains/ spike.

The combined mean performance for all genotypes during two seasons was presented in (Supplementary Table 2). The overall GY (t/ha) of the second season for all genotypes was about 0.77 the recorded values ( $4.93 \mathrm{vs.} 3.81 \mathrm{t} / \mathrm{ha}$ for the first and the second seasons, respectively. data not shown) with mean values $4.41 \mathrm{t} / \mathrm{ha}$ over two season. The superiority of GY under salt-affected soil for each studied genotype had expressed differently. Stable superior productivity across the two seasons of the study had expressed by the genotypes coded $4,11,12,14,16,18,20,22$ and 23 . Whereas, the genotypes coded $3,6,8,13,15,19,25,26,27,28,29$ and 30 had showed elastic response to growing season conditions, since yield superiority was only confined to the first season. The combined yield average un-discussable since the genotype $\times$ season interaction was significant.

No. grain over all the two study seasons, explained the stability of yield superiority for genotypes coded 17, 18, 22, $23,25,26,28$ and 30 , whereas, it's influence to GY superiority for the rest of genotypes was unclear, 1000-GW (g) supported the elasticity of genotype response to variable seasonal conditions for genotypes coded 13 and 20 whereas; its contribution was indefinite for the rest of cultivars.

\section{Plant culture and salinity treatments}

The mean squares of germination percent ( $\mathrm{G} \%$ ) and seedling characters for twelve selected genotypes (representing tolerant and sensitive) showed in (Table 2). Characters of seedlings were recorded to trace the effect of salinity. Genotypes expressed significant differences in germination percentage, Shoot length (SL), shoot dry weight (SDW) and root dry weight (RDW). Also, significant salinities $\times$ genotype interaction had detected in all measured characters, except for, root fresh weight (RFW).

The salinity levels and genotypes mean are presented in (Supplementary Table 3) Significant substantial reduction in $(\mathrm{G} \%$ ) was obtained with salinity level increase. The rate of $\mathrm{G}$ $\%$ reduction over genotypes reached $16.24 \%, 27.43 \%$ and $43.1 \%$ for levels 12,16 , and $20 \mathrm{dSm}-1$, respectively. Seedling characters expressed by SL, RL, SFW, RFW, SDW and RDW, exhibit significant substantial reduction with salinity level increase from $12 \mathrm{dSm}-1$ until $20 \mathrm{dSm}-1$. Attained growth reduction was $\geq 80 \%$ at $20 \mathrm{dSm}-1$ for shoot and root dry weights. While, RFW had severely affected by salinity levels increase relative to SFW (reductions of 26, 57, 40, 70 and $45,80 \%$ for shoot and root fresh weights at salinity levels 12,16 and $20 \mathrm{dSm}-1$, respectively).

The interaction effects of (salinity levels $\times$ genotypes) for twelve barley genotypes were presented in (Supplemental Table 4). Genotypes coded 4, 5, 15, 27 and 30 enjoyed over 90\% (G \%) under the level 12 and $16 \mathrm{dSm}-1$ except for, genotype coded 27 and 30 under $16 \mathrm{dSm}-1$. Also, over $70 \%$ $(\mathrm{G} \%)$ had recorded by the aforementioned genotypes under the high salinity level $20 \mathrm{dSm}-1$ except for genotype coded 30 was $52.43 \%$. Genotype coded 13 , showed sensitivity to salinity levels, where, recorded (G \%) of 76.14, 52.43 and 29.57 under the three studied levels respectively, in spite of genotype coded 8 exhibited a good performance under control specially (RL), but quickly degradation in most characters under the three salinity levels (Supplemental Fig. 1).

\section{Microsatellite markers analysis}

Most of the primer pairs used in this study generated polymorphic bands among the genotypes. A total of 59 alleles were detected among the 30 barley genotypes with an average of 2.4 alleles per locus (Table 3 ). The number of alleles per locus ranged from 1 to 6 in Bmac0030 on chromosome $4 \mathrm{H}$. The average genetic diversity and polymorphism information content (PIC) values observed were 0.24 and 0.22 , respectively. The PIC values for the microsatellite loci ranged from 0.033 for $(\mathrm{Bmac0096}, 5 \mathrm{H}$ and EBmac0603, 7H) to 0.67 for $(B m a c 0030,4 H)$. The mean heterozygosity for the $25 \mathrm{SSR}$ primer pairs was about 0.059 . The components of genetic diversity of each marker obtained with an average data availability of $91 \%$ are shown in (Table 3 ). The major allele frequency had an average of 0.823 with a range extended from 0.40 to 1.0 (data not shown).

\section{Cluster analysis of DNA polymorphism}

The genetic relationships among 30 barley genotypes based on SSR data are presented in a UPGMA dendrogram (Fig 1). All genotypes clearly grouped into four major branches (clusters). The genetic similarity was ranged from $0.22 \%$ 
Table 1. The analysis of variance for five traits of thirty barley genotypes combined over the study seasons.

\begin{tabular}{lcccccc}
\hline & & \multicolumn{5}{c}{ Mean squares } \\
\cline { 3 - 7 } S.O.V & DF & GY & No. Grain & $1000-$ G.W & LA & CHL \\
\hline Season (S) & 1 & $55.78^{* *}$ & $56.67^{\text {n.s }}$ & $2228.1^{* *}$ & $30950^{* *}$ & $814.9^{* *}$ \\
Rep $\times$ season & 4 & 2.331 & 12.11 & 75.16 & 360.10 & 18.20 \\
Genotypes (G) & 29 & $1.971^{* *}$ & $268.68^{* *}$ & $65.42^{* *}$ & $673.06^{* *}$ & $40.85^{* *}$ \\
S $\times$ G & 29 & $1.629^{* *}$ & $23.98^{\text {n.s }}$ & $22.50^{*}$ & $10.95^{* *}$ & $37.07^{* *}$ \\
Combined error & 116 & 0.328 & 31.37 & 14.04 & 73.6 & 16.94 \\
\hline CV\% & & 13.10 & 10.14 & 8.23 & 17.20 & 10.80 \\
\hline
\end{tabular}

GY; grain yield (ton/h), No. Grain; Number of grains per spike, 1000-G.W; 1000 grain weight, LA; flag leaf area and CHL; total chlorophyll content.

*, **; indicate significance at 0.05 and 0.01 levels, respectively, n.s; not significantly different Inter.; interaction.

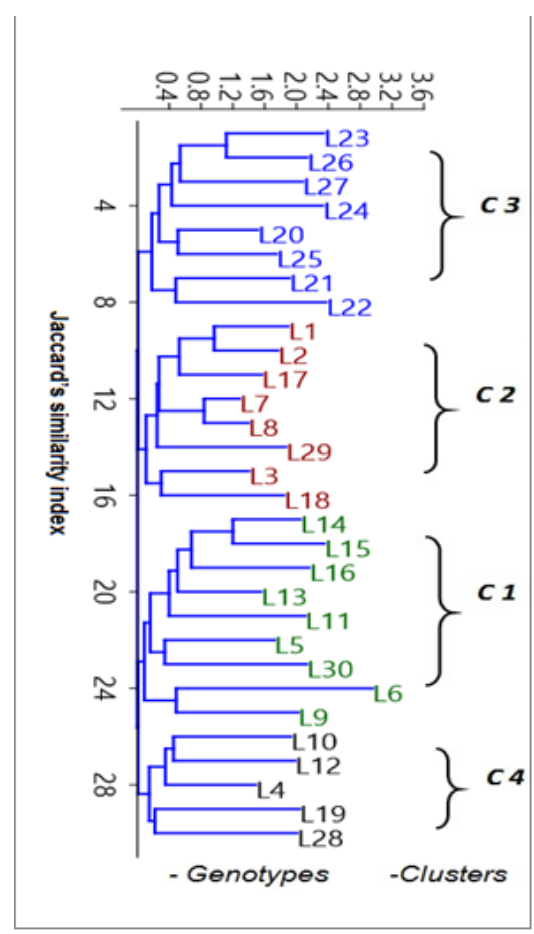

Fig 1. UPGMA tree describing genetic relationships among the thirteen barley accessions based on SSR markers. Genetic distances were calculated based on $\mathrm{Nei} / \mathrm{Li}$ genetic distances. Consistency of the tree topology was evaluated by boot- strapping over loci (10,000 reps).

and reached to $0.85 \%$ between lines 14 and 15 in $\mathrm{C} 1$ cluster according to Jaccard similarity index, indicating magnitude of genetic diversity among the elite genotypes. Most of tolerant and moderate genotypes were located in $\mathrm{C} 1$ and $\mathrm{C} 4$ clusters. On the other hand, the sensitive genotypes 23, 26 and 27 were located in the $\mathrm{C} 3$ cluster with genetic similarity $0.82 \%$ between line 23 and line 26 . While, the remaining sensitive genotype; Lines 2, 8, 18 were distributed in $\mathrm{C} 2$ cluster. Most results of UPGMA cluster analysis was in agreement with field evaluation, which indicated that these genotypes were closely related to each other and in general, this is reflected from their response to salt stress performance during the field evolution. The principal coordinate analysis (PCA) for all genotypes was performed based on genetic distance using 25 SSR markers. The PCA 1 recorded $51.53 \%$ of the total variance, meanwhile PCA 2 showed $7.27 \%$ (Fig 2 ), which was a good informative and agree with the UPGMA cluster results (Fig 1.)

Table 2. The mean square of germination percentage and seedling characters for twelve barley genotypes under four salinity levels.

\begin{tabular}{|c|c|c|c|c|c|c|c|c|}
\hline \multirow[b]{2}{*}{ S.O.V } & \multirow[b]{2}{*}{ DF } & \multicolumn{7}{|c|}{ Mean squares } \\
\hline & & $\mathrm{G} \%$ & SL & RL & SFW & RFW & SDW & RDW \\
\hline Treatments (salt) & 3 & $58.40 * *$ & $426.8 * *$ & $95.6 * *$ & $0.073 *$ & $0.140 * *$ & $0.012 * *$ & $0.005^{* *}$ \\
\hline Rep $\times$ Salt error a & 8 & 0.30 & 0.46 & 0.64 & 0.015 & 0.018 & 0.0001 & 0.00001 \\
\hline Genotypes (G) & 11 & $6.09 * *$ & $14.2 * *$ & 5.60n.s. & 0.015 n.s. & $0.006^{\text {n.s. }}$ & $0.002 * *$ & $0.001 * *$ \\
\hline $\mathrm{S} \times \mathrm{G}$ & 33 & $1.63 * *$ & $5.1 * *$ & $2.01 * *$ & $0.023 *$ & $0.009^{\text {n.s. }}$ & $0.001 * *$ & $0.001 * *$ \\
\hline Error b & 88 & 0.40 & 0.29 & 0.34 & 0.013 & 0.011 & 0.00001 & 0.00001 \\
\hline C.V. \% & & 11.38 & 5.39 & 10.71 & 2.09 & 12.73 & 2.27 & 3.87 \\
\hline
\end{tabular}

G \%; germination \%, SL; Shoot length, RL; root length, SFW; Shoot fresh weight, RFW; root fresh weight, SDW; shoot dry weight and RDW; root dry weight. *and **; indicate significance at 0.05 and 0.01 levels, respectively and n.s; not significantly different. 


\section{Association analysis}

Based on the GLM model, a total of 16 markers- trait associations were identified for the five yield-related traits, ( Table 4). Among the 16 significant associations, six were correlated with GY, six with No. grain, three with 1000-GW, one with LA and five with CHL. The six SSR-trait associations related to the GY; two SSR loci; Bmag0120 and AF022725A on chromosome $7 \mathrm{H}$ with common significant specific alleles $248 \mathrm{bp}$ and $124 \mathrm{bp}$, respectively. The six SSRtrait associations related to No. grain involved two SSR loci; Bmag0011 and Bmag0120 on chromosome 7H. The three SSR-trait associations related to $1000-\mathrm{GW}$ involved 2 SSR loci; EBmac0602 (198, 210 bp) and Bmac0316 (316 bp) on chromosome $7 \mathrm{H}$. The five SSR-trait associations related to CHL involved three SSR markers; Bmac0030, HVMLOH1A and EBmac0701 on chromosome 4H. Moreover, Five SSRtrait associations; Bmag0120, Bmac0316, Bmac0030, EBmac0501 and EBmac0701 were detected in the most traits over two years.

\section{Linkage disequilibrium (LD)}

Differences in effective population size and breeding history are expected to generate different patterns of LD, which would affect the design of association studies using this material. In Fig 3, we show the decay of average $\operatorname{LD}\left(\mathrm{r}^{2}\right)$ with recombination distance across the genome. The squared allele-frequency correlations $\mathrm{r}^{2}$ and the $\mathrm{P}$ value representing linkage disequilibrium LD were assessed for the 25 SSR loci. Significant LD between markers existing in the same linkage group and intra-chromosomal loci $(\mathrm{P}$ value < 0.05) are indicated as well as their $r^{2}$ values (Supplementary Table 5).

\section{Discussion}

In the present study, No. grain of barley genotypes showed elastic response to changing seasonal conditions where, insignificant season $\times$ genotype interaction had obtained (Table 1). Commonly, the anticipation of the studied yield component characters, i. e; No. grain and 1000-GW, to GY superiority stability or plasticity was not independent of the unstudied characters(Amer et al., 2012b; Abd El-Aty et al., 2011), especially the number of spike- bearing tillers. Our results also suggest that, estimates of grain yield might bring another complexity to the salinity response, not just because the crops must be grown in controlled environments for long periods of time, but also due to complexity of the conversion of shoot biomass into the grain (Sadeghi, 2011). The fact that grain yield may not decrease until a given ('threshold') salinity is reached (Maas and Hoffman, 1977). Regarding the vegetative characters, i.e.; LA and CHL, barley genotypes expressed a responsive value to seasonal changes. In the meantime, barley genotypes that showed larger LA or high CHL were not essentially those of high grain yield, Superiority in grain yield might depend on other plant characters related to root functionality (Amer et al., 2012a; Eleuch et al., 2008).

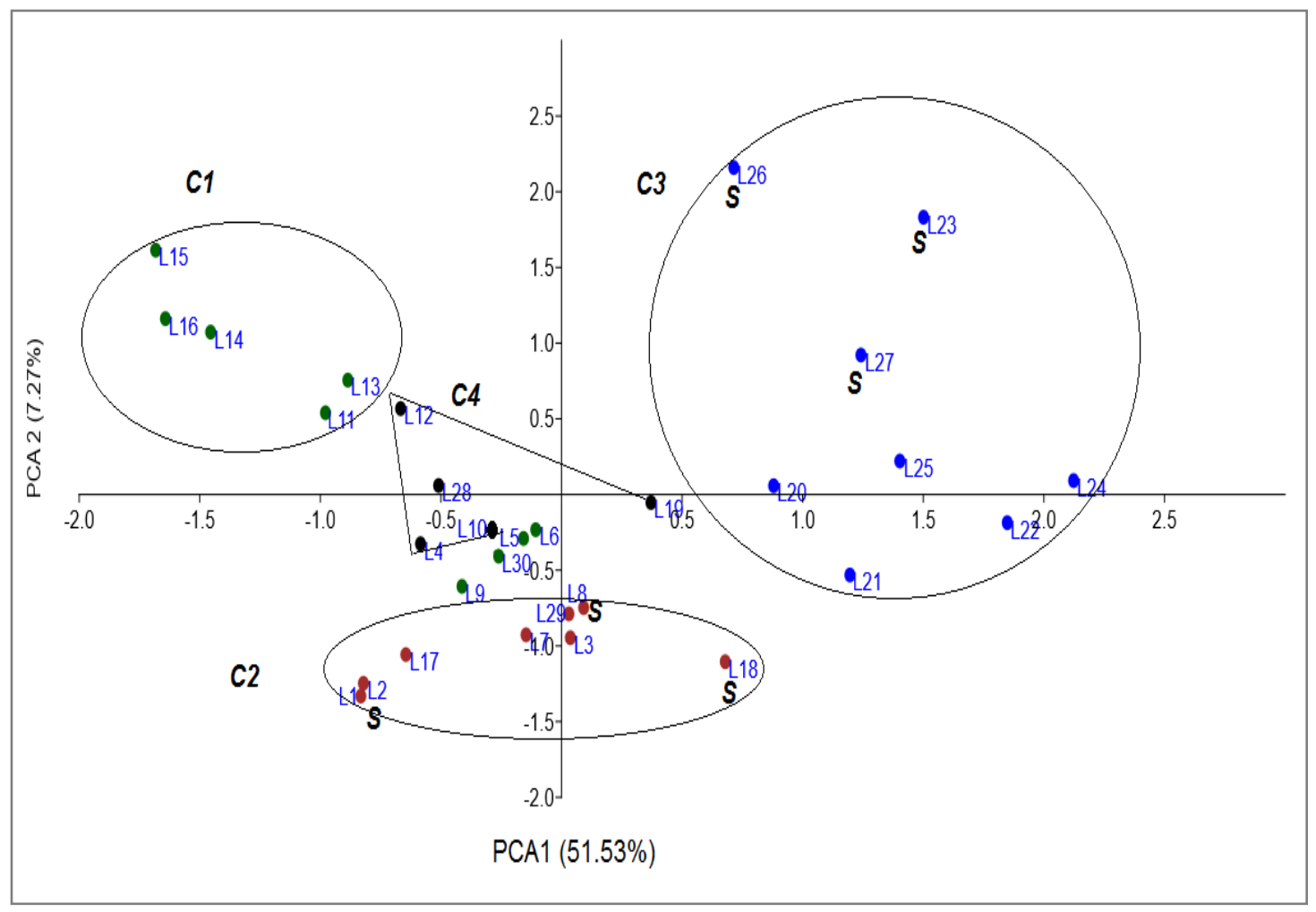

Fig 2. Principal components analysis of 30 elite accessions based on the analysis of 25 SSRs. Genetic similarities among accessions have been calculated as the proportion of loci with shared alleles. The accessions, have been chosen to represent the genetic diversity present in Egypt; local and exotic materials. Where, L numbers; genotypes name, C number; clusters numbers, S; salt sensitive genotypes. 
The reduction in shoot length is due to excessive accumulation of salts in the cell wall elasticity. Further, secondary cell appears sooner and wall becomes rigid as a consequence the turgor pressure efficiency in cell enlargement decreases (Taghipour and Mohammad, 2008). Germination is complicate phenomenon comprising physiological and biochemical variation due to embryo activation. Salinity as a non-live stress makes many hardships for seed in germination period. Salinity decrease water availability for the seed by taking down osmotic potential and in second stage cause to toxicity and change in enzyme activity Massai et al. (2004). The aforementioned seedling results were true for shoot and root length where, the attained levels of growth reduction corresponding to salinity of 12,16 and $20 \mathrm{dSm}^{-1}$ were; 26; 38, 41; 48 and 56; $55 \%$ for SL and RL, respectively (Supplementary Table 3). Reduction in growth with increased salinity levels might be due to limited supply of metabolites to young growing tissue as a result of either metabolic disturbance or low water uptake along with toxic effects of sodium Adjel et al. (2013). High external concentrations of $\mathrm{Cl}^{-}$had similar adverse effects as high concentrations of $\mathrm{Na}^{+}$, suggesting that $\mathrm{Cl}^{-}$toxicity may reduce growth Tavakkoli et al. (2010). Fundamental differences in salinity responses appeared between soil and solution culture, and the importance of the different mechanisms of damage varies according to the severity and duration of the salt stress Ehsan et al. (2010). Saline soils have many dissolved salts including cation and anion. The most prevailing cation and anion are $\mathrm{Na}^{+}, \mathrm{Mg}^{2+}, \mathrm{K}^{+}, \mathrm{Cl}^{-}$and $\mathrm{So}^{2}$. Plant growth and development in saline soil is scanty due to high osmotic pressure that finally cause to reduction in water availability. Also direct toxicity resulted from abundant presence of this ions have a preventive effect on plant and at last this interaction put some limitation for plant growth Homaee et al. (2002). Shoot length was indicative to germination salinity tolerance for genotypes coded 4,5 and 30. Meanwhile, RL was independent from germination salinity tolerance, since was not associated with the obtained $\mathrm{G} \%$ that was true for shoot fresh weight, root fresh weight and root dry weight (Supplementary Table 4), (El Goumi et al., 2014; Yousofinia et al., 2012; Mahmood 2011). Salt stress determines a diversion of root metabolism towards the synthesis of osmolytes, such as glycine betaine and proline, and increased levels of reduced glutathione Cardi et al. (2015). The increase of salt concentration had a negative effect on germination for which the rate decreased; this result has also been reported by El Madidi et al. (2004).

In the present study, SSR markers were able to discriminate between the 30 barley genotypes studied. Primers (Bmac0030 and EBmac0701 on chromosome $4 \mathrm{H}$, got a high value of PIC 0.673 and 0.558, respectively. Furthermore, primer Bmag0125 on chromosome $2 \mathrm{H}$ with PIC value 0.567 (Table 3 ), these markers were sufficient to differentiate all of the genotypes since they generated a high number of allele with high PIC values. The results indicated that this region of chromosome $4 \mathrm{H}$ is important for salt tolerance in barley it may be assumed that there is a QTL cluster for salt tolerance in the region of chromosome $4 \mathrm{H}$, and thus the region may be used as an important target for improving salt tolerance of barley Xue et al. (2009). The PIC value (0.38) obtained by Pillen et al. (2000), who used 22 microsatellite markers and a set of 28 mainly German barley cultivars and two wild forms. The observed alteration in the DNA fragments of barley cultivars exposed to salinity stress may be attributed to the activation of the defence responsive genes, whose transcripts and expression are controlled under salinity stress. Markers validation in independent genotypes of different genetic background is essential in determining the effectiveness and reliability of the markers to predict phenotypic similarity (Collins et al., 2003; Cakir et al., 2003), which indicated that, SSR marker could be used in routine screening for markerassisted selection (MAS). Markers should also be validated by testing for the presence of the markers on arrange of cultivars and other important genotypes. Therefore, markerassisted selection for salinity tolerance could be genotype tolerant specific. Interestingly enough, our findings indicated the potential efficacy of highly informative SSR markers for efficient screening of brewing barley genotypes.

All the 30 genotypes were clustered to four groups with the same genotypes. Genetic distance (Fig. 1) was ranged from $42 \%$ to $85 \%$ (data not shown), indicating magnitude of genetic diversity among the elite genotypes. Obviously, the $\mathrm{C} 1$ cluster which represented showed higher genetic diversity $85 \%$ followed by C3 cluster $82 \%$ (data not shown). It is obvious that the adaptation of barley to saline soils is different among the genotypes with diverse genetic backgrounds. In addition, the physiological and molecular markers would be useful in screening different cultivars for their tolerance against salt stress during breeding programs of barley Abdel-Hamid, (2014). In barley, important traits such as salt tolerance are controlled by polygene with additive and dominant effects that were described by quantitative trait loci (QTLs) Ellis et al. (2000). Genetic relationships between barley genotypes revealed by genetic similarity at SSR levels were in agreement with their roles in agricultural production and breeding Karakousis et al. (2003) argued the usefulness of polymorphic SSR markers for the discrimination of barley. The PCA was performed to compare the distribution of the genotypes based on genetic distance. Four possible groups of genotypes were found and agree with UPGMA cluster analysis (Fig. 1 and Fig. 2). Eleuch et al. (2008), showed that Cluster and principal coordinate analysis allowed a clear grouping between 48 barley genotypes were analyzed with 22 (SSR) markers. Principal Components Analyses is also used to remove correlation among independent variables that are to be used in multivariate regression analysis.

\section{LD and association analysis}

The molecular marker data set in combination with phenotype evaluation was used to examine linkage-related marker-trait associations (LD). The markers pairs (Bmag770 and EBmac0501, in chromosome 1H); (EBmac0701 and Bmac0030 4H); (Bmac0316 and Bmag0009 6H) and (AF022725A and Bmag0120, 7H in addition to, EBmac0603 and $\mathrm{AF} 022725 \mathrm{~A}, 7 \mathrm{H}$ ), were found to be associated with salinity and showed linkage disequilibrium with $\mathrm{r} 2$ values higher than 0.05, Zhang et al. (2009) (Supplementary Table 5). Based on the GLM model, the marker-trait associations were identified for the five yield-related traits during two season and were subjected to elevated salinity in the soil (Table 4). Association analysis along with specific significant alleles of grain yield (GY) showed a significant association of the marker Bmag749 (2H,176bp) with salinity, Eleuch et al. (2008) reported association analysis for grain yield under salinity conditions revealed a close association of the marker Bmag749 (2H, bin 13) in two different environments with common significant alleles $(175,177 \mathrm{bp})$. Markers that have been reported to be associated with salinity like HVCMA and HvLTPPB (Rostokset al. 2005) and EBmac0415, EBmac0871 and Bmac0096 (Bahieldin et al., 2005; Heshamet al., 2005) did not show any association with salinity tolerance in this study. Salt tolerance is a complex inherited trait and it is likely that several QTLs but also 
Table 3. Summary of the diversity analysis components revealed by simple sequence repeat (SSR) markers.

\begin{tabular}{|c|c|c|c|c|c|c|c|c|c|c|}
\hline No & SSR Locus & Motif & Ch. L & $\begin{array}{c}\text { Size } \\
\text { bp }\end{array}$ & Allele No. & $\begin{array}{c}\text { Availability } \\
\text { a }\end{array}$ & $\begin{array}{c}\text { Gene } \\
\text { Diversity }\end{array}$ & $\begin{array}{c}\text { Heterozygosity } \\
\mathrm{b}\end{array}$ & PIC & $\begin{array}{c}\text { Annealing } \\
*\end{array}$ \\
\hline 1 & EBmac0501 & (AC) 13 & $1 \mathrm{H}$ & 151 & 3 & 0.93 & 0.4388 & 0.00 & 0.38 & $\mathrm{~A}$ \\
\hline 2 & Bmac0154 & (AT)19 (AC)6 & $1 \mathrm{H}$ & 130 & 3 & 1.00 & 0.1561 & 0.10 & 0.15 & A \\
\hline 3 & Bmag770 & $(\mathrm{GT}) 13(\mathrm{AG}) 19$ & $1 \mathrm{H}$ & 158 & 4 & 1.00 & 0.1861 & 0.20 & 0.18 & B \\
\hline 4 & Bmag382 & $(\mathrm{AG}) 7$ AA(AG)7 & $1 \mathrm{H}$ & 109 & 1 & 0.97 & 0.0000 & 0.00 & 0.00 & A \\
\hline 5 & Bmac0213 & $(\mathrm{AC}) 23$ & $1 \mathrm{H}$ & 168 & 1 & 0.97 & 0.0000 & 0.00 & 0.00 & A \\
\hline 6 & Bmag0125 & (AG)19 & $2 \mathrm{H}$ & 134 & 3 & 1.00 & 0.6400 & 0.00 & 0.57 & $\mathrm{~B}$ \\
\hline 8 & Bmag749 & $(\mathrm{AG}) 11$ & $2 \mathrm{H}$ & 166 & 1 & 0.93 & 0.0000 & 0.00 & 0.00 & A \\
\hline 9 & EBmac0871 & (TG)13 & $3 \mathrm{H}$ & 180 & 3 & 0.87 & 0.5769 & 0.00 & 0.50 & B \\
\hline 10 & HvLTPPB & $(\mathrm{AC}) 10(\mathrm{AT}) 5$ & $3 \mathrm{H}$ & 221 & 1 & 0.87 & 0.0000 & 0.00 & 0.00 & B \\
\hline 11 & Bmac0209 & $(\mathrm{AC}) 13$ & $3 \mathrm{H}$ & 176 & 2 & 0.97 & 0.3662 & 0.00 & 0.30 & A \\
\hline 12 & $\mathrm{Bmac} 0030$ & $(\mathrm{AC}) 22$ & $4 \mathrm{H}$ & 155 & 6 & 1.00 & 0.7189 & 0.90 & 0.70 & A \\
\hline 13 & EBmac0701 & (AC) 23 & $4 \mathrm{H}$ & 149 & 3 & 0.77 & 0.6314 & 0.00 & 0.56 & B \\
\hline 14 & HVMLOH1A & (GA)6 & $4 \mathrm{H}$ & 175 & 1 & 0.87 & 0.0000 & 0.00 & 0.00 & B \\
\hline 16 & Bmac0113 & (AT) 7 (AC) 18 & $5 \mathrm{H}$ & 187 & 1 & 0.90 & 0.0000 & 0.00 & 0.00 & A \\
\hline 17 & HvLOX & (AG) 9 & $5 \mathrm{H} / 6 \mathrm{H}$ & 150 & 3 & 0.43 & 0.1450 & 0.16 & 0.14 & A \\
\hline 18 & EBmac0602 & $(\mathrm{AC}) 9 \mathrm{AT}(\mathrm{AC}) 7(\mathrm{AG}) 9$ & $6 \mathrm{H}$ & 205 & 3 & 0.97 & 0.5375 & 0.00 & 0.50 & A \\
\hline 19 & Bmag0009 & $(\mathrm{AG}) 13$ & $6 \mathrm{H}$ & 172 & 2 & 0.97 & 0.1855 & 0.00 & 0.17 & A \\
\hline 20 & Bmac0316 & (AC) 19 & $6 \mathrm{H}$ & 135 & 3 & 0.97 & 0.4905 & 0.03 & 0.44 & B \\
\hline 21 & Bmag0120 & $(\mathrm{AG}) 15$ & $7 \mathrm{H}$ & 230 & 4 & 1.00 & 0.4883 & 0.03 & 0.43 & A \\
\hline 22 & HVCMA & (AT) 9 & $7 \mathrm{H}$ & 141 & 2 & $0 . \mathrm{Z3}$ & 0.0768 & 0.00 & 0.07 & A \\
\hline 23 & AF022725A & (TG) 8 & $7 \mathrm{H}$ & 136 & 2 & 0.90 & 0.1372 & 0.00 & 0.13 & A \\
\hline 24 & Bmag0011 & (AG) 25 & $7 \mathrm{H}$ & 147 & 2 & 0.97 & 0.3282 & 0.00 & 0.27 & A \\
\hline \multirow[t]{3}{*}{25} & EBmac0603 & (CA) 10 & $7 \mathrm{H}$ & 149 & 2 & 0.97 & 0.0339 & 0.03 & 0.03 & A \\
\hline & Mean & & & & 2.4 & 0.92 & 0.2468 & 0.0596 & 0.22 & \\
\hline & Total & & & & 59 & & & & & \\
\hline
\end{tabular}

- Ch. L; Chromosomal Location, a; Percentage of available data, b; Percentage of heterozygote genotypes; PIC: Polymorphism information content.

- $*^{\mathrm{A}}$ Annealing temp., $58^{\circ}$ C. $-*^{\mathrm{B}}$ Annealing temp., 55.

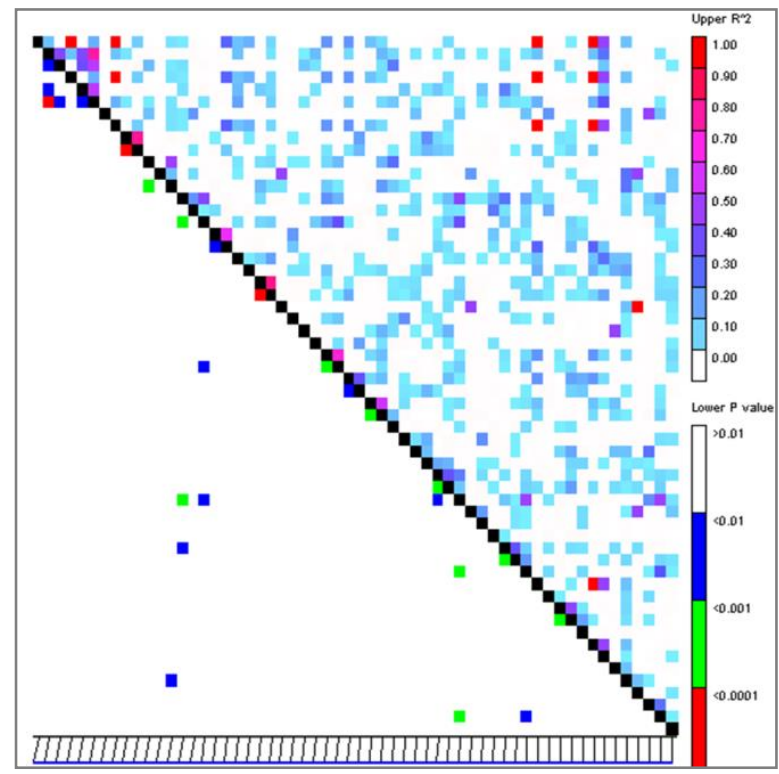

Fig 3. Linkage disequilibrium matrix. Pair-wise LD values of polymorphic sites displaying $r 2$ above the diagonal and the corresponding $p$-values from rapid1000 shuffle permutation test below the diagonal. Each cell represents the comparison of two pairs of marker sites with the colour codes for the presence of significant LD.

several different mechanisms are involved Mazzucotelli et al. (2008). Although a large number of SSR markers are available in barley, they have been developed and mapped in different mapping populations. Ideally, all markers should be mapped in the same mapping population Varshney et al. (2007). However, the limited polymorphism in current study has not allowed all possible SSR markers to be mapped onto a single genetic map. An alternative way to prepare a dense SSR genetic map is to combine the different and available genetic maps by exploiting common bridging markers. Consensus maps including various types of molecular markers have been developed before in several species, e.g. 
Table 4. SSR loci significantly associated with five traits and the significance [- $\log (\mathrm{P}-\mathrm{value})]$ based on the GLM model.

\begin{tabular}{llccc}
\hline Trait & Loci & Chr. & Position (cM) & Significant alleles (bp) \\
\hline GY & Bmac0030 & $4 \mathrm{H}$ & 58.60 & 110 \\
& Bmag0120 & $7 \mathrm{H}$ & 97.00 & 248 \\
& Bmag749 & $2 \mathrm{H}$ & 117.86 & 176 \\
& Bmag382 & $1 \mathrm{H}$ & 81.40 & 105 \\
& AF022725A & $7 \mathrm{H}$ & 45.80 & 124 \\
\multirow{5}{*}{ No. Grain } & HvLOX & $5 \mathrm{H}$ & 122.34 & 145 \\
& Bmag0011 & $7 \mathrm{H}$ & 81.78 & 188 \\
& EBmac0501 & $1 \mathrm{H}$ & 64.84 & 148 \\
& Bmac0316 & $6 \mathrm{H}$ & 7.16 & 180 \\
& EBmac0701 & $4 \mathrm{H}$ & 96.17 & 154 \\
1000-GW & Bmag0125 & $2 \mathrm{H}$ & 89.83 & 248 \\
& Bmag0120 & $7 \mathrm{H}$ & 97.00 & $198-210$ \\
& EBmac0602 & $6 \mathrm{H}$ & 75.42 & 156 \\
LA & Bmac0316 & $6 \mathrm{H}$ & 7.16 & 178 \\
CHL & Bmac0213 & $1 \mathrm{H}$ & 30.81 & $111-305$ \\
& Bmac0154 & $1 \mathrm{H}$ & 87.83 & 93 \\
& Bmac0030 & $4 \mathrm{H}$ & 58.60 & 130 \\
& EBmac0501 & $1 \mathrm{H}$ & 64.84 & 180 \\
& HVMLOH1A & $4 \mathrm{H}$ & 102.27 & 233 \\
& Bmag770 & $1 \mathrm{H}$ & 54.60 & 133 \\
\hline
\end{tabular}

Table 5. The chemical and physical characteristics of soil samples during the two seasons.

\begin{tabular}{|c|c|c|c|c|c|c|c|c|c|c|c|}
\hline \multicolumn{6}{|c|}{ Soil samples properties } & \multicolumn{4}{|c|}{ Soluble cationsmeq/L } & \multicolumn{2}{|c|}{ Water samples properties } \\
\hline season & $\mathrm{pH}$ & $\operatorname{ECe}\left(\mathrm{dsm}^{-1}\right)$ & $\mathrm{CaCO}_{3} \%$ & ESP \% & SAR \% & $\mathrm{Ca}^{++}$ & $\mathrm{Mg}^{++}$ & $\mathrm{Na}^{++}$ & $\mathrm{K}^{+}$ & $\mathrm{pH}$ & $\operatorname{ECe}\left(\mathrm{dsm}^{-1}\right)$ \\
\hline 1 st & 7.83 & 10.90 & 3.95 & 52.9 & 8.9 & 20.70 & 40.30 & 47.05 & 0.95 & 5.3 & 2.3 \\
\hline 2nd & 8.41 & 9.5 & 2.32 & 51.7 & 8.4 & 51 & 30.6 & 53.5 & 0.4 & 5.5 & 2.1 \\
\hline \multicolumn{6}{|c|}{ Soluble anions $\mathrm{meq} / \mathrm{L}$} & \multicolumn{6}{|c|}{ Physical properties } \\
\hline season & $\mathrm{SO}_{4}$ & $\mathrm{Cl}^{-}$ & $\mathrm{HCO}_{3}$ & $\mathrm{CO}_{3}$ & Sand $\%$ & $\begin{array}{l}\text { Silt } \\
\%\end{array}$ & Clay $\%$ & \multicolumn{4}{|c|}{ Texture class } \\
\hline 1 st & 38.87 & 67.00 & 3.13 & - & 23.80 & 24.90 & 51.30 & \multicolumn{4}{|c|}{ Clayey } \\
\hline 2nd & 72.5 & 60 & 3 & - & 16.7 & 33.27 & 50.03 & \multicolumn{4}{|c|}{ Clayey } \\
\hline
\end{tabular}

barley (Langridge et al., 1995; Qi et al., 1996; Karakousiset al., 2003).

\section{Materials and Methods}

\section{Plant genetic materials and phenotyping}

A field trial was conducted at Sakha Agricultural Research station, Egypt on thirty Egyptian elite hulls barley genotypes during the two successive winter seasons 2012/2013 and 2013/2014 (Supplementary Table 1). The experimental design was a randomized complete block design (RCBD) with three replications. Genotypes have divided to two "sets" each of 15 genotypes. Plot size was four rows, $2 \mathrm{~m}$ long and $0.2 \mathrm{~m}$ apart. Data had collected random from the central rows in each plot. The recorded characters included; total chlorophyll content (CHL), flag leaf area (LA), number of grains per spike (No. Grain), 1000- grain weight (1000-GW) and grain yield (GY) (ton/ha $\left.{ }^{-1}\right)$.

\section{Soil characteristics}

At harvesting, soil samples were taken from the upper soil layer $(0-30 \mathrm{~cm})$ to conduct the chemical and physical analysis (Table 5) according to Black et al. (1965).

\section{Growth chamber conditions}

The trials were conducted in a growth chamber and molecular analysis at the Institute of Genetic Resources, Faculty of
Agriculture, Kyushu University, Japan. Based on the field evaluation, the best performing genotypes under saline soil condition (ten genotypes, i.e.; coded 12, 29, 13, 15, 4, 5, 7, 30,14 and 20) along with the most sensitive genotypes (two genotypes, i.e.; coded 8 and 27) were selected. The selected genotypes were germinated under controlled conditions, at $20-25{ }^{\circ} \mathrm{C}$, relative humidity of $55-60 \%$ and 16 hours light period under four concentrations of sodium chloride $(\mathrm{NaCl})$ and Calcium chloride $\left(\mathrm{CaCl}_{2} \cdot 2 \mathrm{H}_{2} \mathrm{O}\right)(\mathrm{W} / \mathrm{W})$. The four combinations were; $\mathrm{Lo}=$ distilled water $\left(\right.$ control), $\mathrm{L}_{1}=7680$ ppm $\left(\mathrm{Ec}=12 \mathrm{dSm}^{-1}\right.$ and $\left.\mathrm{pH}=5.40\right), \mathrm{L}_{2}=10240 \mathrm{ppm}(\mathrm{Ec}=16$ $\mathrm{dSm}^{-1}$ and $\left.\mathrm{pH}=5.55\right)$, and $\mathrm{L}_{3}=12800 \mathrm{ppm}\left(\mathrm{Ec} 20 \mathrm{dSm}^{-1}\right.$ and $\mathrm{pH}=5.58)$. Each plot was represented by five seeds sown to a plastic pot $(2 \mathrm{~cm}$ diameter) filled with artificial soil. A factorial arrangement of twelve genotypes by four irrigation water salinity levels (total of 48 treatments) were carried out in a completely randomized design (CRD) with three replicates. Data of shoot and root length, fresh and dry weight were recorded for the five seedling in each plot.

\section{Statistical analysis}

Data were statistically analyzed following the analysis of variance procedure (ANOVA) by using statistical programmed MSTAT-C Russel, (1996). Least Significant Difference test was used to compare means at 0.05 and 0.01 levels. 


\section{Polymorphism of microsatellite markers}

Leaf tissues (100 -150 mg) were ground to a fine powder by using a grinding mill "MULF BEADS SHOCKER® and used for DNA extraction. The sequences of microsatellite primer pairs were downloaded from Grain Genes data base http://wheat.pw.usda .gov/cgi-bin/graingenes/report.cgi. The markers were selected based on; responsive to abiotic stress (Varshney et al., 2007; Rostoks et al., 2005; Ramsay et al., 2000) and their uniform distribution in the barley genome.

\section{PCR amplification}

DNA was isolated by CTAB method (Doyle and Doyle 1990). The PCR amplification was performed in a total volume $10 \mu \mathrm{L}$ and the bands were detected with Ethidium Bromide staining and visualized under UV light, then photographed on Gel Documentation.

\section{Genotypic data analysis and data scoring}

The polymorphic microsatellite markers were characterized by the amplification of the genomic DNA. Molecular weight was analyzed by GelAnalyzer 2010 (version: 2010a freeware; www.gelanalyzer.com). The number of alleles, availability, gene diversity, Heterozygosity, polymorphic information content (PIC) and genetic distance coefficients were calculated using Powermarker version 3.25 (Liu and Muse 2005). PIC was calculated using the following formula: PIC $=1-\sum x_{k}^{2}$. Values were calculated for each of the microsatellite loci Nei, (1973). Where $\mathrm{x} \_k$ represents the frequency of the k_th allele. The distance matrix was used to construct a typical cluster scheme revealing associations among countries and samples based on the UPGMA with bootstrapping 100 times using the PAST program Hammer et al. (2001). According on Nei's genetic distance, the principal components analysis (PCA) between 30 barley genotypes were carried using 25 SSR markers Jaccard, (1912).

\section{Linkage disequilibrium and Association mapping analysis}

LD was estimated using the squared allele frequency correlations ( $\mathrm{r} 2$ ), which is a measurement of the correlation between a pair of variables (Hill and Robertson, 1968). The expected decay of LD was modelled as per (Weir and Hill, 1986). The association between the phenotypes and markers were evaluated with general linear model (GLM) in TASSEL v 5.2.16 (http://www.maizegenetics.net/) (Bradbury et al. 2007, Zhang et al. 2010). The phenotypic allele effect of SSR that associated with five traits was estimated through comparison between the average phenotypic values over accessions with the specific allele.

\section{Conclusions}

Improving salt tolerance can be achieved by selecting parental genotypes before crossing based on microsatellite markers additionally, the evaluating and selecting salt tolerance among genotypes are not easy tasks because measurements of physiological and morphological phenotypes are highly affected by environmental factors. In order to use the results of the association analysis, we assessed the phenotypic allele effect of each SSR that associated with five yield-related traits and a number of elite allele was detected associated with five yield-related traits. A small sample and limited markers were used in this study and the results need to be confirmed using linkage mapping or a large association population. However, the results are credible because many of the loci that were identified were associated with traits that were common with previous reports of linkage or association mapping. These will be useful for molecular marker assist selection and molecular design breeding.

\section{Acknowledgments}

This work was supported by cultural Affairs\& Mission sector in Egypt and Laboratory of Plant Genetic Resources, Institute of Genetic Resource, Faculty of Agriculture, Kyushu University, Japan.

\section{References}

Abd El-Aty M, Amer Kh, Eldegwy I, Elakhdar A (2011) Genetic studies on yield and its components in some barley crosses. J Plant Prod Mansoura Univ. 2(11):1537- 1550.

Abdel-Hamid A (2014) Physiological and molecular markers for salt tolerance in four barley cultivars. Eur Sci J. 10 (3): 252272.

Adjel F, Kadi1 Z, Bouzerzour H, Benmahammed A (2013) Salt stress effects on seed germination and seedling growth of barley (Hordeum Vulgare L.) genotypes. J Agric Sust. 3: 223237.

Amer Kh, Eid A, Elakhdar A, El-Shawy E (2012a) Combining ability and heterosis in five barley genotypes for some economic traits. Egyptian J Agric Res. 90: 105-116.

Amer Kh, Eid A, El-Sayed M, Elakhdar A (2012b) Estimation of some genetic parameters for yield and its components in some barley genotypes. Egyptian J Agric Res. 90: 117-130.

Bahieldin A, Mahfouz H, Eissa H, Saleh O, Ramadan A, Ahmed I (2005) Field evaluation of transgenic wheat plants stably expressing the HVA1 gene for drought tolerance. Physiol Plant. 123: 421-427.

Barrett-Lennard E (2003) The interaction between water logging and salinity in higher plants: causes, consequences and implications. Plant Soil. 253: 35-54.

Bartlett M (1937) Properties of sufficiency and statistical tests. Proceedings of the Royal Society of London. Series A, Math and Phys Sci. 160 (901): 268-282.

Black C, Evans D, Ensminger L, White J, Clark F (1965) Methods of soil analysis. part 2. Agronomy Monograph 9. ASA and SSSA Madison, Wiley, New Yourk. P 383-390.

Bradbury P, Zhang Z, Kroon D, Casstevens T, Ramdoss Y, Buckler E (2007) TASSEL: Software for association mapping of complex traits in diverse samples. Bioinformatics. 23: 26332635.

Cakir M, Gupta S, Platz G, Ablett G, Loughman R, Emebiri L, Poulsen D, Li C, Lance R, Galwey N, Jones M, Appels R (2003) Mapping and validation of the genes for resistance to pyrenophora teres $\mathrm{f}$. teres in barley (Hordeum vulgare L.). Aust J Agr Res. 54 (12): 1369-1377.

Cardi M, Daniela C, Myriam F, Gea G, Maurizio C, Sergio E (2015) The effects of salt stress cause a diversion of basal metabolism in barley roots: Possible different roles for glucose-6-phosphate dehydrogenase isoforms. Plant Physiol Bioch. 86: 44-54.

Cockram J, White J, Zuluaga D, Smith D, Comadran J, Macaulay M, Luo Z, Kearsey M, Werner P, Harrap D, Tapsell C, Liu H, Hedley P, Stein N, Schulte D, Steuernagel B, Marshall D, Thomas W, Ramsay L, Mackay I, Balding D, Waugh R, Sullivan D, Consortium A (2010) Genome-wide association mapping to candidate polymorphism resolution in the unsequenced barley genome. Proc Natl Acad Sci USA. 107: 21611-21616.

Collins H, Panozzo J, Logue S, Jefferies S, Barr A (2003) Mapping and validation of chromosome regions associated with high malt extract in barley (Hordeum vulgare L.). Aust $\mathbf{J}$ Agr Res. 54 (12): 1223-1240. 
Colmer T, Munns R, Flowers T (2005) Improving salt tolerance of wheat and barley: future prospects. Aust J Exp Agr. 45: 1425-1443.

Doyle J and Doyle J (1990) Isolation of plant DNA from fresh tissue. Focus. 12 (1): 13-15.

Ehsan T, Pichu R, McDonald G (2010) The response of barley to salinity stress differs between hydroponic and soil systems. Funct Plant Biol. 37 (7): 621-633.

El Goumi Y, Fakiri M, Lamsaouri O, Benchekroun M (2014) Salt stress effect on seed germination and some physiological traits in three Moroccan barley (Hordeum vulgare L.) cultivars. J Mater Environ Sci. 5 (2): 625-632.

El Madidi S, El Baroudi B, Bani Aameur F (2004) Effects of salinity on germination and early growth of barley (Hordeum vulgare L.) cultivars. Int J Agric Biotechnol. 6767-770.

Eleuch L, Jilal A, Grando S, Ceccarelli S, Korff M, Tsujimoto H, Hajer A, Daaloul A, Baum M (2008) Genetic diversity and association analysis for salinity tolerance, heading date and plant height of barley germplasm using simple sequence repeat markers. J Integr Plant Biol. 50 (8): 1004-1014.

Ellis R, Forster B, Robinson D, Handley L, Gordon D, Russell J, Powell W (2000) Wild barley: a source of genes for crop improvement in the $21^{\text {st }}$ century? J Exp Bot. 51 (342): 9-17.

Garland S, Lewin L, Abedinia M, Henry R, Blakeney A (1999) The use of microsatellite polymorphisms for the identification of Australian breeding lines of rice (Oryza sativa L.). Euphytica. 108: 53- 63.

Hammer $\varnothing$, David A, Ryan D (2001) Paleontological statistics software package for education and data analysis. Palaeontol Electron. 4 (1): 9-18.

Harlan J (1976) Barley. Evolution of crop plants. In: Simmonds N W (ed) Longman, London, p 93-98.

Hesham F, Callista B, Alexandra N, Mariam B (2005) Barley HVA1 gene confers salt tolerance in R3 transgenic oat. Crop Sci. 45: 2218-2227.

Hill W, Robertson A (1968) The effects of inbreeding at loci with heterozygote advantage. Genetics. 60 (3): 615-628.

Homaee M (2002) Plants Response to Salinity. Iranian National Committee on Irrigation and Drainage (IRNCID). No. 58, Tehran. Iran.

Jaccard P (1912) The distribution of the flora in the alpine zone. New Phytologist. 11 (2): 37-50.

Jaiwal P (1997) Strategies for improving salt tolerance in higher plants. In: Flowers T, Yeo A, (ed) Breeding for salt resistance in plants, Scientific Publisher, Enfield, New Hampshire.

Karakousis A, Gustafson J, Chalmers K, Barr A, Langridge P (2003) A consensus map of barley integrating SSR, RFLP and AFLP markers. Aust J Agr Res. (54): 1173-1185.

Langridge P, Karakousis A, Collins N, Kretschmer J, Manning S (1995) A consensus linkage map of barley. Mol Breed. 1:389395.

Liu K and Muse S (2005) Power Marker: an integrated analysis environmentfor genetic marker analysis. Bioinformatics. 21: 2128-2129.

Maas E, Hoffman G (1977) Crop salt tolerance-current assessment. J Irrig Drain Div. 103 (2): 115-134.

Mackay I, Powell W (2007) Methods for linkage disequilibrium mapping in crops. Trends Plant Sci. 12: 57-63.

Mahmood K (2011) Salinity tolerance in barley (Hordeum Vulgare L.): Effects of varying $\mathrm{Nacl}, \mathrm{K}^{+} / \mathrm{Na}^{+}$and $\mathrm{NaHCO}_{3}$ levels on cultivars differing in tolerance. Pak J Bot. 43 (3): 1651-1654.

Massai R, Remorin D, Tattini M (2004) Gass exchange, water relation and osmotic adjustment in two scion/rootstock combination of prunus under various salinity concentrations. Plant Soil. 259: 153-162.

Mazzucotelli E, Anna M, Mastrangelo, Crosatti C, Guerra D, Stanca M, Cattivelli L (2008) Abiotic stress response in plants: When post-transcriptional and post-translational regulations control transcription. Plant Sci. 174: 420-431.

Nei M (1973) The theory and estimation of genetic distance. In: Morton NE (ed) Genetic Structure of Populations. University Press of Hawaii, Honolulu. 45-54.
Nordborg M, Tavare S (2002) Linkage disequilibrium: what history has to tell us. Trends Genet. 18:83-90.

PillenV, Binder A, Kreuzkam B, Ramsay L, Waugh R, Förster J, Léon J (2000) Mapping new EMBL-derived barley microsatellites and their use in differentiating German barley cultivars. Theor Appl Genet. 101: 652-660.

Powell W, Machray G, Proven J (1996) Polymorphism revealed by simple sequence repeats. Trends Plant Sci. 7 (1): 215-222.

Pritchard J, Stephens M, Rosenberg N, Donnelly P (2000) Association mapping in structured populations. Am J Hum Genet. 67:170-181.

Qi X, Stam P, Lindhout P (1996) Comparison and integration of four barley genetic maps. Genome. 39:379-394.

Ramsay L, Macaulay M, Degli S, MacLean K, Cardle L, Fuller J, Edwards K, Tuvesson S, Morgante M, Massari A, Maestri E, Marmiroli N, Sjakste T, Ganal M, Powell W, Waugh R (2000) A simple sequence repeat-based linkage map of barley. Genetics. 156: 1997-2005.

Rostoks N, Mudie S, Cardle L, Russell J, Ramsay L, Booth A, Jan S, Steve I, Walia H, Mario E, Peter E, Liu H, Morris J, Timothy J, David F, Robbie W (2005) Genome-wide SNP discovery and linkage analysis in barley based on genes responsive to abiotic stress. Mol Genet Genomics. 274: 515527.

Russel D (1996) MSTAT Director. Crop and soil science department, Michigan state university, USA.

Sadeghi H (2011) Use of new barley cultivar to improve salt tolerance and yield in cultivated barley (Hordeum vulgare L .). Afr J Agr Res. 6 (20): 4778-4784.

Saghai-Maroof M, Biyashev R, Yang G, Zhang Q, Allard R (1994) Extraordinarily polymorphic microsatellite DNA in barley: species diversity, hromosomal locations, and population dynamics. Paper presented at the $91^{\text {st }}$ Proceedings of the National Academy of Sciences of the United States of America, 5466-5470 June 1994.

Storey R, Wyn R (1978) Salt stress and comparative physiology in the gramineae. I. Ion relations of two salt- and waterstressed barley cultivars, California Mariout and Arimar. Aust J Plant Physiol. 5:801-816.

Taghipour F, Mohammad S (2008) The study of salt tolerance of iranian barley (Hordeum vulgare $L$.) genotypes in seedling growth stages. Am Eur J Agri Env Sci. 4 (14): 525-529.

Tavakkoli E, Rengasamy P, McDonald G (2010) The response of barley to salinity stress differs between hydroponic and soil systems. Funct Plant Biol. 37: 621-633.

Varshney R, Marcel T, Ramsay L, Russell J, Röder M, Stein N, Waugh R, Langridge P, Niks R, Graner A (2007) A high density barley microsatellite consensus map with 775 SSR loci. Theor Appl Genet. 6 (114): 1091-1103.

Weir B, Hill W (1986) Nonuniform recombination within the human beta-globin gene cluster. Am J Hum Genet. 38 (5): 776781.

Xue D, Youzong H, Xiaoqi Z, Kang W, Sharon W, Chengdao L, Mingcan C, Guoping Z, Reg L (2009) Identification of QTLs associated with salinity tolerance at late growth stage in barley. Euphytica. 169 (2): 187-196.

Yousofinia M, Alireza G, Sofalian O, Saeed K (2012) Effects of salinity stress on barley (Hordeum vulgare L.) Germination and seedling growth. Int J Agr Crop Sci. 4(18): 1353-1357.

Zhang L, Marchand S, Nicholas A, Tinker, Belzile F (2009) Population structure and linkage disequilibrium in barley assessed by DArT markers. Theor Appl Genet. 119: 43-52.

Zhang Z, Ersoz E, Lai C, Todhunter R, Tiwari H, Gore M, Bradbury P, Yu J, Arnett D, Ordovas J, Buckler E (2010) Mixed linear model approach adapted for genome-wide association studies. Nature Genetics. 42: 355-360.

Zhu C, Gore M, Buckler ES, Yu J (2008) Status and prospects of association mapping in plants. Plant Genome 1: 5-20. 